\title{
LAS REMINISCENCIAS DE PEREDA
}

\author{
Salvador GARCÍA CASTAÑEDA \\ The Ohio State University
}

Según Philippe Lejeune, la autobiografía es un «récit rétrospectif en prose qu'une personne réelle fait de sa propre existence, lorsqu'elle met l'accent sur sa vie individuelle, en particulier sur l'historie de sa personnalité» («Pacte» 8). Estos acontecimientos van enmarcados en el contexto de otros de orden político y cultural en los que ha participado o de los que ha sido testigo. La autobiografía suele estar escrita en primera persona del singular y adopta un punto de vista retrospectivo aunque el orden cronológico tiende a estar frecuentemente modificado por la intrusión de preocupaciones personales (May, 1979, pág. 214). El autobiógrafo escribe obsesionado por el paso del tiempo, por el deseo de comprenderse a sí mismo o de hacerse comprender de los demás y por vanidad. Como señala repetidamente Georges May, el autobiógrafo se remonta a sus orígenes, lo cual es otra manera de explicar el papel privilegiado que tienen en tantas autobiografías los recuerdos de la infancia y de la adolescencia (167).

En cambio, en las memorias, «l'auteur se comporte comme un témoin: ce qu'il a personnel, c'est le point de vue individuel, mais l'objet du discours est quelque chose qui dépasse de beaucoup l'individu, c'est l'histoire des groupes sociaux et historiques auquel il appartient» (Lejeune, 1982, pág. 15). Los límites entre la autobiografía y las memorias son imprecisos y subjetivos pues en la composición de muchas obras hay unos elementos que pertenecen a las memorias y otros a la autobiografía y de estos dos elementos uno está subordinado al otro. Lo que importa es ver si el propósito fundamental del autor ha sido escribir la historia de su persona o la de su época (Lejeune, 1982, págs. 15-16). El autor / narrador / personaje de memorias hace un relato retrospectivo de su propia existencia 
como testigo de un pasado que considera tan importante como para ser trasmitido a las generaciones futuras.

Contrariamente a la opinión tan extendida en el pasado de que los españoles no eran dados a escribir su propia biografía o sus memorias, es hoy de dominio común que nuestra literatura cuenta, concretamente en el siglo XIX, con una apreciable cantidad de autores que cultivaron estos géneros (Caballé). Entre ellos no figura Pereda, aunque la lectura de sus obras nos revela cerca de una veintena de textos en los que éste aparece como protagonista, como personaje o como testigo de hechos que tuvieron lugar en el pasado. Todos son relatos autodiegéticos en los que protagoniza cada una de estas historias, narradas en primera persona.

Cuando estudiaba en Madrid confesaba éste en carta del 9 de Diciembre de 1853 a su primo Domingo Cuevas «el demasiado apego» que iba sintiendo por la vida de la corte a costa de «la pluviosa e insípida Montaña» pero regresó al cabo de dos años para integrarse dentro de la vida santanderina. Conocida es la poderosa influencia que ejerció la madre sobre la constitución espiritual de Pereda, complementada por la del hermano mayor Juan Agapito, quien encarnó la del padre. A juicio de Francisco Pérez Gutiérrez, la razón de tan breve ausencia se debió a que «el demasiado apego a la corte era tanto como la huida del país natal, que psicoanalíticamente significaba la huida de la madre, y el subsiguiente complejo de culpa debió ser lo suficientemente intenso como para que el joven Pereda regresara al cabo de dos años al país natal y al seno materno...» (1992, pág. 326).

A partir de su vuelta, la vida de Pereda se centra en el periodismo y en la crítica teatral, en la publicación de sus libros, en las tertulias y en las estancias en Polanco durante el verano. La atracción que sintió antaño por Madrid se convertirá en fobia y todos sus afectos se concentrarán en Santander y en el clan de sus amigos santanderinos. Entre los artículos que publica, muchos se refieren a la vida social -espectáculos, el veraneo y los bailes- y otros tienen que ver con obras públicas, mejoras urbanas, sucesos diarios y gentes de la ciudad. Varios de aquéllos, debidamente modificados, reaparecerían después como artículos de costumbres. Y algunos de los elementos contenidos en ellos se incorporarían también a sus novelas (García Castañeda, 1992, págs. 33-39).

Con el paso del tiempo Pereda comienza a rememorar sobre el pasado y lo hace en artículos dedicados enteramente a sus recuerdos, dos de los cuales llevan el título de «reminiscencias», en narraciones de carácter diverso, en prólogos a obras propias o ajenas, y en artículos periodísticos y cartas publicadas en la prensa. La mayoría de las autobiografías comparten dos características comunes: «la primera es que la autobiografía es producto de la edad madura, si no lo es de 
vejez; la segunda, que los autores son ya conocidos del público antes de publicarla» Generalmente, éstos suelen escribirlas hacia la cincuentena (Lamartine, Rousseau, Gide, Simone de Beauvoir) muchas otras son bastante más tardías (Goethe a los 62 años; Darwin a los 67). Y algunas son excepcionalmente tempranas como la del poeta inglés George Moore, quien escribió la suya a los 36 (May, 1979, págs. 30-31) Lo que sorprende en Pereda es lo tempranamente que comienza a rememorar y su artículo «El raquero» que contiene recuerdos infantiles vio la luz en 1863 cuando su autor contaba tan sólo 30 años. A partir de entonces las reminiscencias del pasado irán apareciendo a lo largo de veintitrés años hasta 1886, cuando contaba 53, la edad en la que otros autores suelen comenzar a ocuparse nostálgicamente del pasado. Estas reminiscencias tienen carácter autobiográfico por la evocación de la infancia y de la pubertad del autor $y$, a la vez, de memorias pues evocan unas gentes y una ciudad ya idas. De hecho, Pereda describió las costumbres de su tierra cuando nadie lo hacía y su obra es hoy imprescindible para conocer muchos aspectos del Santander y de la Montaña del siglo XIX.

A veces los autobiógrafos escriben acerca de cosas y de circunstancias que en principio no interesan al lector pero que a él le son queridas y estas cosas a veces resultan más emotivas que otros pasajes (May, 1979, págs. 104-105). Así le ocurre a Pereda, quien escribe «Pero observo, pacientísimo lector, que me salgo del terreno de nuestro objeto, evocando estas memorias que a ti no te importan un bledo. Perdóname generoso este descuido» (Pereda, OC: I, pág. 520) Lo que cuenta el autor de su propia vida puede reflejar, inesperadamente, algo semejante en la del lector pues no es posible arrojar luz sobre aquélla sin que alcance de algún modo la de los demás. Cuanto más entra un autor en sus reminiscencias y multiplica más los detalles concretos y al parecer fútiles, su emoción nos parece más familiar y más reconocemos la nuestra en ella. Y como los recuerdos de un autor son comparables a los nuestros cuando ambos pertenecemos a una misma cultura, a una misma época, al mismo país, al mismo medio social o simplemente a una misma hermandad de espíritu (May, 1979, pág. 109).

Pereda pide al lector contemporáneo suyo que se sitúe en el mismo plano sincrónico y que sirva de testigos de lo que cuenta, y al rememorar el desaparecido Muelle Anaos escribe en 1863: «Muchos lectores se acordarán, como yo me acuerdo, de su negro y desigual pavimento, ...» y al concluir su descripción, insiste: «De nada de esto se habrán olvidado, porque el Muelle de las Naos, efecto de su libérrimo gobierno, ha sido siempre, para los hijos de Santander, el teatro de sus proezas infantiles» (El raquero, OC: I, págs. 7-18). Un año después, tenía entonces Pereda 31, al evocar con tono entre nostálgico y épico «las famosas 
pedreas...», «las sangrientas batallas» $\mathrm{y}$ «las inolvidables troncadas» juveniles advertía que «aún no peinan canas muchos de los personajes que llevaban la mejor parte en empresas que más de dos veces degeneraron en trágicas» (El primer sombrero, $O C$, II, pág. 236). Esbozos y rasguños iba precedido de un prólogo dedicado a su gran amigo Manuel Marañón en el que defendía los artículos que formaban el libro frente a la posible reacción negativa de los críticos porque «pasan de media docena los lectores que la esperan [esta obra] y han de juzgarla por el mismo lado que usted y yo, porque fueron unos actores y otros testigos presenciales de los sucesos, y hasta de la pintura de ellos, y saben y aprecian el por qué de cada trazo y el motivo de cada línea» (OC, II, pág. 44). Otro «Prólogo», el de Sotileza (1884), tan nostálgico que nos inclinaría a creerlo escrito por un anciano aunque es obra de un hombre de 51 años, está dirigido a «A mis contemporáneos de Santander que aún vivan.» En él insiste en que el libro no pertenece a la escuela naturalista ni toca los grandes temas de moda entonces porque «no es más que un pretexto para resucitar gentes, cosas y lugares que apenas existen ya y reconstruir un pueblo, sepultado de la noche a la mañana, durante su patriarcal reposo, bajo la balumba de otras ideas y otras costumbres arrastradas hasta aquí por el torrente de una nueva y extraña civilización». Al autor no le preocupa lo que piensen los críticos de Sotileza sino aquellos a quienes va dedicada: «Así Dios me salve como no he pensado en otros lectores que vosotros al escribir este libro. Y declarado esto, declarado queda, por ende, que a vuestros juicios le someto y que sólo con vuestro fallo me conformo. [...])Y quién, sino vosotros, podrá suplir con la memoria fiel lo que no puede representarse con la pluma...». $\mathrm{Y}$ concluye con la esperanza de que la novela guste tanto a esos lectores que al terminarla le digan: «Choca esos cinco, porque eres de nuestra calle...» (OC, VI, págs. 63-68)

En ocasiones quienes escriben acerca de su propio pasado lo hacen con ironía o con humor acerca de las acciones, palabras o pensamientos del personaje que él mismo fue antaño. Jean Starobinski ha observado en las Confesiones de Rousseau la presencia de dos tonos: el picaresco, en el que el autor habla del suyo con ironía, con condescendencia, con piedad, o con alegría, y el tono elegíaco en el que el acento cualitativo favorece al pasado en detrimento del presente. (Cit. por May, 1979, pág. 82). Buenos ejemplos del primero serían este autorretrato de los tiempos de estudiante en el Instituto: «Robustote y fuerte por naturaleza, y hasta gordinflón (quantum mutatus ab illo!), a pesar de mis catorce años representaba diez y nueve, circunstancia que no dejaba de darme alguna preponderancia entre mis condiscípulos, sobre todo, entre los que eran más débiles que yo». 
(El primer sombrero, OC, II, págs. 238-239), y unas líneas en las que se retrata con irónica condescendencia a los 19 años cuando fue invitado a formar parte de la elegante sociedad de los bailes campestres: «La primera vez que se me buscó a mí con tal objeto, creí desmayarme de emoción; y con mano trémula escribí un SI tan gordo como dos ciruelas [...] en las listas de socios para los bailes de campo no figuraba sino lo escogido de la juventud del pueblo, según el criterio de la comisión; de manera, que verse llamado por ella en lances semejantes, era la declaración solemne y oficial, no solamente de que salía uno de la categoría de chiquillo y entraba en la de mozo, sino en la de mozo distinguido, activo y útil. No era uno masa, no era vulgo» (Los bailes campestres, OC, I, pág. 227)

Autobiografías y memorias suelen contener elementos de carácter regional y aún folklórico relacionados con el lugar de origen del autor. Además de su valor anecdótico, estos elementos sirven para señalar su anclaje histórico y cultural. Recordar la infancia, la juventud y los amigos va ligado a calles, a rincones y a gentes y Pereda quiso conservar la memoria de cosas entrañables para que no desapareciesen con él, y en «El espíritu moderno», refiriendose al futuro de Escenas montañesas afirma que «En ese día alcanzará algun éxito este libro [...] depositario fiel de las costumbres de un pueblo patriarcal y hospitalario, no carecerá de atractivo para la curiosidad de los nuevos explotadores del suelo virgen que me le ha dictado» (OC, I, pág. 263).

«Creo que fue Madame de Sevigné -escribía- quien dijo que sucede con los recuerdos lo que con las cerezas en canastilla: se tira de una y salen muchas enredadas. Los evocados en el cuadro anterior (Reminiscencias) traen a mi memoria mil, íntima y necesariamente encadenados a ellos» (Más reminiscencias, $O C$, II, pág. 323). Además de ser testigo de sí mismo el autor lo es de lo que le rodea y aunque no pretenda hacer historia no puede dejar de sufrir la influencia de su ambiente y de escribir en función de esta influencia. Y refiriéndose a la popularidad de la autobiografía con el público lector, se preguntaba Roland Barthes, «¿Por qué [...] en las obras históricas, novelescas, biográficas, hay (para algunos, entre los que me encuentro yo) el placer de ver representada «la vida cotidiana» de una época, de un personaje? )Por qué esta curiosidad por los pequeños detalles: horarios, costumbres, comidas, habitaciones, vestidos etc?» (Cit. por May, 1978, pág. 100). En su evocación sentimental de un Santander mágico visto a través de sus ojos de niño, Pereda nos va mostrando olvidados rincones de la ciudad, tiendas desaparecidas hace lustros, calles que ya no existen y gentes pintorescas de antaño. Sin pretenderlo, hace costumbrismo en torno a sí mismo y detalla festividades, juguetes y juegos infantiles, vestimenta, estudios y el parco modo de vivir de entonces, de gran valor para la historia social de su tiempo. 
Nuestros recuerdos van ligados a aquellos lugares en los que tuvieron lugar nuestros felices recuerdos, «los lugares lejanos y desaparecidos, se convierten en guardianes privilegiados de la memoria» (Hernández Álvarez, 1993, págs. 241-245). Buen ejemplo de ello sería la bella y melancólica evocación de los desaparecidos árboles de la Alameda, que asociaba con la de su propia infancia:

porque ese paseo, de ramas abajo, de punta a punta, de lado a lado, paso a paso y detalle por detalle, le sabía yo de corrido desde que andaba yo a la escuela; porque quizás no ha germinado desde entonces un pensamiento en mi cabeza, desde los más pueriles hasta los más trascendentales para mi vida, que no le tuviera yo asociado en la memoria con algo de lo que allí se ha destruido. Con el oscilar de la rama, las manchas del tronco, el rumor del follaje, el sillar de este banco, el respaldo del otro... todos aquellos ámbitos augustos que guarda tan fielmente recuerdos que yo les había confiado, recuerdos de mis juegos infantiles, de mis ilusiones de muchacho, de mis aspiraciones de mozo y de mis realidades y desengaños de hombre con canas; y todos estos recuerdos, en tropel unas veces y otras en sosegado desfile, me salían al encuentro cada día, cuando para orear un poco la trabajada imaginación entre aquellas admirables obras de la naturaleza, penetraba en la penumbra de sus bóvedas con el mismo cariño, con igual amor que entre los viejos muros del hogar en que nací; pues sabido es que el apego a los lugares es obra de los recuerdos que al recorrerlos se despiertan. (Variedades)

Refiriéndose a la definición de Lejeune, escribe Darío Villanueva que en el pacto autobiográfico «se da por supuesto el principio de la sinceridad en el sujeto de la enunciación y el derecho a la verificación por parte de sus destinatarios»(1993, pág. 19). El pacto autobiográfico resulta ser así la confirmación en y por el texto de la identidad real del autor que es a la vez narrador y protagonista. En sus «reminiscencias» el autor / narrador Pereda mantiene una relación testimonial con los hechos y de contacto con los caracteres. Su vida está indisolublemente unida a la de un Santander que se está convirtiendo con rapidez en una ciudad cosmopolita, moderna y próspera, pero tales cambios traen consigo una transformación de las ideas y de las costumbres que no son del agrado de todos. En su evocación de un pasado no conocido [Santander antaño y ogaño] o conocido a través de terceras personas (Dos sistemas) el joven Pereda ve con humorística condescendencia a personajes de generaciones anteriores a la suya como Don Pelegrín Tarín en Santander (antaño y ogaño), la interlocutora del narrador en El espiritu moderno y don Anacleto Remanso en La romería del Carmen que se aferran a lo antiguo, temen los cambios y se asustan de las novedades. 
Aunque en repetidas ocasiones (Un marino, El primer sombrero, Reminiscencias, Más reminiscencias, Sres. Redactores del Santander-Crema, Sr. D. Ricardo Olaran) relata algunas costumbres bárbaras del viejo Santander de su juventud en términos censorios o compasivos («la implacable persecución de los infelices») advierte que «entonces se consideraba como natural, lo que hoy llaman crueldades», y evoca otras costumbres como los escándalos organizados por los marinos o los zarrapastrosos carnavales de antaño con evidente nostalgia y simpatía.

Todo esto visto desde la perspectiva del Santander del presente, después de los grandes cambios; Pereda señala dos épocas; la primera, hacia el año 50, con la construcción del ferrocarril, el veraneo de los forasteros en Santander y de los santanderinos en la aldea, así como la popularidad de nuevas modas y costumbres que caracterizó irónicamente como «ese airecillo que aclimató la crinolina en Bezana y la cerveza en San Román» (Un marino, $O C$, I, pág. 213). En la parte I (1852) de El espíritu moderno es partidario de la evolución de las costumbres y de las mejoras traídas por el tren y las líneas de vapores y del embellecimiento de Santander y de Comillas, lugares ya de veraneo a la moda; en la II, lamenta que tales novedades acaben con las costumbres tradicionales y con la felicidad patriarcal aldeana; y en la III (1864), concluye que «Los pueblos ilustrados ya no tienen costumbres propias. Los de la Montaña cuando acaben de ilustrarse, no han de ser menos que ellos» (OC, I, pág. 263).

La segunda época de cambios llegó con la Revolución del 68, contra cuyo espíritu e ideas luchó Pereda siempre, y especialmente desde las páginas de El Tío Cayetano (1868-1869). Y muchos años más tarde, en 1883, el desilusionado Pedro Sánchez opinaba que «Al movimiento renovador y reformista iniciado ya con brío a mi salida de España, había sucedido la revolución política de 1868 , harto más radical y demoledora que la del 54, en que tan activa parte había tomado yo. El primero transformó el aspecto exterior de los pueblos; la segunda influyó grandemente en el modo de pensar de los hombres; y al impulso de estos dos agentes poderosos, la sociedad salió de sus antiguos cauces, y entróse por otros nuevos; creóse la vida distintas necesidades, y se transformaron radicalmente las costumbres.» (Pedro Sánchez, OC, V, pág. 670). A juicio de Pereda, el Santander pintoresco, el de los «tipos» amados por los costumbristas, desaparecería simbólicamente con la muerte de Tremontorio, poco después de la galerna del sábado de Gloria de 1878: «La raza indígena pura, del mareante santanderino, tal cual existía aún, desde tiempo inmemorial, diez u once años ha, iba en aquel ataúd a enterrarse con Tremontorio» (El fin de una raza. OC, I, pág. 252). 
En la frase inicial de Pedro Sánchez, «Entonces no era mi pueblo la mitad de lo que es hoy», destaca Pérez Gutiérrez las palabras entonces y hoy; la primera, representa el comienzo y desarrollo del relato, y hoy, la perspectiva desde la que escribe el narrador. Mi pueblo es la realidad única que se anhela como invariable y eterna pero que en los años transcurridos ha ido cambiando y ha terminado por desaparecer. «Cuando concluyamos la lectura del libro entenderemos hasta qué punto la frase es una lamentación, un quejido absoluto, una desaprobación sin paliativos del tiempo histórico y de la pretensión de la realización en su transcurso del individuo» (1992, págs. 326-327)

Lo mismo que las autobiografías y las memorias estas reminiscencias son literatura de evasión y al revivir sus recuerdos Pereda se refugia en los dulces sueños de un pasado lejano para huir del presente. A veces el sentimiento es tan intenso que hace renacer la sensación y la emoción de entonces («Pues, señor, en aquel tiempo tuvo un pariente mío la desdichada ocurrencia de regalarme un sombrero de copa. ¡Me parece que le estoy viendo!» (El primer sombrero, OC, II, págs. 238-239)

Al transmitir nuestros recuerdos a la posteridad, escribimos también sobre la vida de los demás $\mathrm{y}$, al evocar la desaparecida Alameda, escribe Pereda:

...Todo Santander acudía allí: los elegantes, a media tarde, de paso para la Alameda Segunda, y de vuelta de ésta, hasta el anochecer; los niños a todas horas, y los viejos a las más cómodas para tomar el sol en invierno y la sombra en verano, sin el estorbo y los ruidos de las muchedumbres. (Cuántas generaciones ha visto uno pasar así, por aquellas naves grandiosas! (Cuántas caras recuerda, cuántos nombres, cuántas historias, cuántas veleidades de la fortuna, cuántas virtudes y cuántas miserias del corazón! [...]

Después se trasformaron las costumbres; llevó la rutina de la moda el paseo de las gentes elegantes al extremo opuesto de la población, y nos quedamos solos en la Alameda Primera los niños, los pájaros, los ancianos, y unos cuantos desperdigados de poco más o menos. Entonces me pareció más venerable que nunca; y esta veneración fue tomando mayor arraigo en mi pecho, a medida que los pensamientos, por virtud del curso de los años, iban sazonándose en la mente y volando por regiones de otra luz, si no tan risueña, más clara que la de la primera mocedad... (Variedades).

Como mencioné anteriormente, el tono melancólico de quienes escriben acerca de su remoto pasado aparece pronto en Pereda y al comenzar la década de los 80 , poco después de haber cumplido él mismo 50 años, el tono se torna desesperadamente elegíaco, más propio de un anciano al borde de la tumba que de un 
hombre en pleno dominio de sus facultades a quien todavía queda por crear la mayor y la mejor parte de su obra literaria. Así escribía en 1884:

[...] soy a modo de mueble inútil, relegado al desván de los trastos viejos, o, si lo quieren de otro modo, lacio, desalentado y taciturno espectador de la comedia nueva, pero tan alejado de ella, que apenas percibo los manoteos y las zancadas de los comediantes. Tan extraño soy a lo que pasa, tan forastero me juzgo en mi propio lugar, que se pasmarían Vds. si yo les dijera de qué cosas me asombro, qué nimiedades me dejan boquiabierto y ante qué casos me detengo, confuso y desorientado, como paleto en la Corte, recién llovido de su aldea...; (Señores redactores); en 1885, (Cuántos éramos... y cuán pocos quedamos ya! (Cómo recuerdo a los muertos, y cómo los recordaba ayer uno por uno, cada vez que entraba en la Alameda para dar en ella mis cotidianos paseos! Deudas sagradas del corazón que nunca se pagan bastante. (Variedades) y en 1886: Aquel apretado escuadrón que formamos durante los alegres juegos de la infancia o en las aulas de la Universidad (cómo va enrareciéndose a medida que el tiempo corre y va empeñándose poco a poco la batalla de la vida! Unos, desertores, otros, rezagados, muertos, los más de ellos (cuán pocos llegamos juntos a trasponer la cumbre donde el hielo de los años calma el ardor de la sangre y emblanquece los cabellos! ¡Con qué ansia nos contamos a cada paso del descenso, $\mathrm{y}$ al vernos tan pocos y tan hostigados por rigor de las contrariedades, qué secreto pavor nos acomete y con qué insaciable afán nos contemplamos y nos unimos! (Don Andrés Crespo).

A pesar de la supuesta ausencia de carácter «ficticio» atribuido canónicamente a las autobiografías dado el pacto autobiográfico entre el narrador y los lectores algunos críticos han señalado la importancia de los elementos de ficción presentes en ellas. Para Georges May «du fait que l' autobiographie est autobiographie, elle n'est pas véridique» (1979, pág. 88). El anotar por escrito el recuerdo que se tiene de un acontecimiento del pasado lleva inevitablemente a un acercamiento $o$ a un enfrentamiento entre el pasado que se recuerda y el presente en que se redacta este recuerdo, probablemente deformado e incompleto. André Maurois en Aspects de la biographie distinguía cinco razones principales por las que una autobiografía resultaba inexacta o mentirosa: el olvido; el olvido voluntario por razones estéticas; la censura natural «que ejerce el espíritu sobre lo que es desagradable»; el pudor; $y$, en fin, «la reconstitution après coup d'une causalité qui avait été sans effet sur le moment» (Cit. por May, 1979, pag. 77). En el caso de Pereda, es obvio que sus «reminiscencias» tienen carácter selectivo, lo que ya implica una falsificación o deformación del recuerdo. Un caso concreto sería el de la muerte de don Bernabé, el temido maestro de latinidad, que ofrece dos versiones diferentes, una más digna que la otra, debidas sin duda a razones estéticas o al olvido (Más reminiscencias, OC, II, 338, nota 15) 
Es casi un lugar común considerar Pedro Sánchez una novela de carácter autobiográfico pues recoge aspectos de la vida de su autor en Madrid, reflejada en la del protagonista. Pérez Gutiérrez observa muy atinadamente que, a través de su personaje, Pereda describió hechos y personas que tuvo ocasión de seguir con sus propios ojos, pero que, a su vez, al tiempo que narra, «se siente distanciado de las actitudes que tuvo y se describe a sí mismo como sujeto entonces de ese mismo distanciamiento [pues] el antiliberal Pereda está escribiendo la biografía equivocada de su personaje» (1992, págs. 337-338).

En ocasiones se trató de pintar a Pereda como un caballero del Siglo de Oro, cosa que le molestaba en extremo pues se consideraba un hombre de su tiempo al que agradaban las comodidades de la nueva tecnología como el ferrocarril o el teléfono y hablaba con orgullo de las mejoras del Santander moderno. A Pereda no le molestaban los cambios, lo que le molestaba era el carácter político y, en consecuencia, social, que tuvieron. Las conmociones del 48 , la revolución de 1854 y la del 68 trajeron ideas nuevas y cambiaron la antigua conformidad por la exigencia de reivindicaciones sociales. En las obras de Pereda aparece la palabra patriarcal («las tradiciones risueñas y el inocente bienestar de los patriarcas», $L a$ romería del Carmen; aquellos «apacibles tiempos de patriarcal parsimonia», Reminiscencias) contrapuesta con frecuencia a la de ilustración, que subraya siempre para indicar que la usa irónicamente («Los pueblos ilustrados ya no tienen costumbres propias. Los de la Montaña cuando acaben de ilustrarse, no han de ser menos que ellos», El espíritu moderno). Para él, ambas representan dos ideologías y dos sistemas políticos muy diferentes.

A pesar de que Pereda contó con buena cantidad de jóvenes admiradores y discípulos deja bien claro su desdén por las costumbres venidas del extranjero -«nos han impuesto el Veloz Club, la high life, el Folklore y tantos otros donaires de tirilla y water proof» y por las modas al uso entre los jóvenes del dia: «¿A qué fin responden [...] ese empeño de lucir las formas, que afemina y rebaja a los bien formados, y convierte en ratas mojadas o en mirlos en carnitas a los encanijados y achacosos, que son los que más abundan?» (Señores redactores).

En estas melancólicas reminiscencias de los años 80 apenas cita nombres pues Pereda evoca el vivir de una generación y unos valores ya idos. Quienes le conocieron han dejado constancia de sus altibajos de humor y de sus obsesiones; según Enrique Menéndez Pelayo, íntimo suyo, tenía «un poder de transformar la impresión más ligera en sensación dolorosa y tremenda, y la más leve contrariedad en conflicto atroz e insoluble» (1906, págs. 18-19). Esta disposición hipersensible de su carácter influyó sin duda a la hora de redactar estas reminiscencias 
que tienen el poder de evocar las maravillas del vivir en un mundo tan feliz como simple.

\section{OBRAS CITADAS}

CABALLÉ, Anna, 1991. «Memorias y autobiografías en España (siglos XIX y $\mathrm{XX}$ )», en Angel G. Loureiro, coord., La autobiografía y sus problemas teóricos. Estudios e investigación documental, Barcelona, Anthropos, págs. 143-169.

CLARKE, Anthony H., 1996. Edición de Sotileza. Introducción y notas de Francisco Caudet en Obras Completas de José María de Pereda, Volumen VI, Santander, Diputación Regional de Cantabria.

GARCÍA CASTAÑEDA, Salvador, 1989. Escenas Montañesas y Tipos y Paisajes. Edición, estudio y notas, en Obras Completas de José María de Pereda, Volumen I, Santander, Diputación Regional de Cantabria.

- 1989. Tipos Trashumantes y Esbozos y Rasguños. Edición, estudio y notas, en Obras Completas de José María de Pereda, Volumen II, Santander, Diputación Provincial de Cantabria.

- 1992. «Del periodismo al costumbrismo: La obra juvenil de Pereda». Romance Quarterly, 39, Núm. 1, págs. 33-39.

HERNÁNDEZ ÁLVAREZ, Vicenta, 1993. «Algunos motivos recurrentes en el género autobiográfico», en Escritura autobiográfica, Madrid, Visor, págs. 241-245

LEJEUNE, Philippe, 1971. L'autobiographie en France, París, Armand Colin.

- 1991. «El pacto autobiográfico», en Loureiro, Angel G., coord., La autobiografía y sus problemas teóricos. Estudios e investigación documental, Barcelona, Anthropos, págs. 47-61.

- 1982. «Le pacte autobiographique (bis)», en L'autobiographie en Espagne, Actes du Colloque international de La Baume les Aix. Université de Provence, págs. 8-25

MAY, Georges, 1979. L'autobiographie, París, Presses Universirtaires de France. 
MENÉNDEZ, Enrique, «Carácter de Pereda», «Gustos y costumbres de Pereda», «Apuntes para la biografía de Pereda», en El Diario Montañés, 1 de Mayo de 1906, Número extraordinario, págs. 19-21.

PEREDA, José María de, 1989. Escenas Montañesas y Tipos y Paisajes. Edición, estudio y notas de Salvador García Castañeda en Obras Completas, I. Santander, Diputación Regional de Cantabria.

- 1989. Tipos Trashumantes y Esbozos y Rasguños. Edición, estudio y notas de Salvador García Castañeda en Obras Completas, II, Santander, Diputación Regional de Cantabria.

- 1996. Sotileza. Edición de Anthony H. Clarke, introducción y notas de Francisco Caudet en Obras Completas, VI, Santander.

- 1992. Pedro Sánchez, Introducción y notas de Francisco Pérez Gutiérrez, edición de José Manuel González Herrán en Obras Completas, V, Santander, Diputación Regional de Cantabria.

- «Señores redactores del Santander-Crema», El Santander-Crema, 20 de Enero de 1884.

- «Variedades. Sr Director de El Aviso. Pido la palabra para una alusión personal», El Aviso, No. 20, 14 de Febrero de 1885

- «Don Andrés Crespo», El Atlántico, 4 de Marzo de 1886.

ROMERA, José, Alicia Yllera y Rosa Calvet, eds, 1993. Escritura autobiográfi$c a$, Madrid, Visor.

L'autobiographie en Espagne, 1982. Actes du Colloque international de La Baume les Aix, Université de Provence.

VILLANUEVA, Darío, 1993. «Realidad y ficción: la paradoja de la autobiografía», en Escritura autobiográfica. Actas del II Seminario Internacional del Instituto de Semiótica Literaria y Teatral, Madrid, Visor. 